\title{
Sulfonated poly(ether ether ketone)-functionalised silica composite membranes for applications in proton exchange membrane fuel cells
}

\author{
Vijay Shankar Rangasamy*, \\ Savitha Thayumanasundaram \\ and Jean-Pierre Locquet \\ Department of physics and Astronomy, \\ Celestijenlaan 200D Box 2414, \\ Heverlee 3001, Belgium \\ E-mail: vijayshankar.rangasamy@fys.kuleuven.be \\ E-mail: savitha.sundaram@fys.kuleuven.be \\ E-mail: jeanpierre.locquet@fys.kuleuven.be \\ ${ }^{*}$ Corresponding author
}

\section{Niels De Greef and Jin Won Seo}

Department of Metallurgy and Materials Engineering,

Kasteelpark Arenberg 44 - bus 2450,

B-3001 Leuven, Belgium

E-mail: niels.degreef@mtm.kuleuven.be

E-mail: maria.seo@mtm.kuleuven.be

\begin{abstract}
Sulfonated Poly(ether ether ketone) (SPEEK) and its composites are explored as potential alternatives for Nafion in fuel cell applications. In this work, we investigate the effects of the silica functionalisation route on the thermal, mechanical and structural properties of SPEEK-Silica composite membranes. We compare two different methods - direct sulfonation and co-condensation (sol-gel) - to add sulfonic acid groups to silica nanoparticles, which are used as fillers in SPEEK membranes. The degree of sulfonation (DS) of the cast membranes determined by ${ }^{1} \mathrm{H}$ NMR ranged from $40 \%$ to $86 \%$. TGA-DSC measurement shows higher desulfonation temperatures for the composite membranes, indicating better thermal stability compared to pure SPEEK membranes. DMA results show that the sol-gel membranes are mechanically more stable with a wider operational temperature range than the directly sulfonated and pristine SPEEK membranes. Water uptake of the membranes increases with silica content, indicating the formation of additional water-mediated pathways for proton conduction.
\end{abstract}

Keywords: SPEEK; silica; PEMFC; sol-gel; sulfonation; dynamic mechanical analysis; DMA; functionalisation; co-condensation; operational temperature range.

Reference to this paper should be made as follows: Rangasamy, V.S., Thayumanasundaram, S., Locquet, J-P., de Greef, N. and Seo, J.W. (2014) 'Sulfonated poly(ether ether ketone)-functionalised silica composite membranes for applications in proton exchange membrane fuel cells', Int. J. Nanotechnol., Vol. 11, Nos. 9/10/11, pp.971-992. 
Biographical notes: Vijay Shankar Rangasamy is a Doctoral student of the Department of Physics and Astronomy in KU Leuven. He has been working on the development of polymer membranes for proton exchange membrane fuel cells (PEMFCs).

Savitha Thayumanasundaram obtained her $\mathrm{PhD}$ in Physics from Bharathiar University, India, with a thesis entitled 'Synthesis and characterisation of Nano-sized electrolyte and electrode materials for Lithium Rechargeable Batteries'. She did her postdoctoral research at the Department of Inorganic Chemistry in the University of Padova, Italy on the development of polymer electrolyte membranes based on Nafion and ionic liquids. Currently, she is working in KU Leuven on material synthesis and characterisation for lithium rechargeable batteries and PEMFCs.

Jean-Pierre Locquet is a Professor at the KU Leuven, Department of Physics and Astronomy and Chairman of the Leuven Nanoscience and Nanotechnology. After his $\mathrm{PhD}$, he joined the IBM Research Laboratory, Zurich as a research staff member and has since then developed the molecular beam epitaxy technique for complex oxides. He has published more than 150 papers with more than 120 in reviewed journals, including in Nature (2) and Science (1) and holds seven patents. In October 2006, he established the Functional Nanosystems group in KU Leuven, specialising in the synthesis of many oxide materials both in thin film form as well as in bulk form.

Niels De Greef is a Doctoral student working on nano-engineered epoxy matrices and focuses on CNT growth on carbon fibres to enhance their mechanical properties.

Jin Won Seo received her PhD in Physics from the RWTH, Aachen in 1995 for her investigation on structural properties of epitaxial oxide thin films by means of HRTEM, which was carried out at the Research Center Jülich. In November 1997, she joined IBM Research Laboratory as a postdoctoral research associate. In January 2002, she became a senior researcher at the Ecole Polytechnique Fédérale de Lausanne (EPFL) as a project leader of the group 'Nanomaterials and characterisation'. Her main expertise is on growth, structural and chemical characterisation of epitaxial oxides and nanomaterials, in particular by means of conventional, analytical (EDS, EELS) and high-resolution TEM. Since May 2007, she is a Professor at the KU Leuven in the Department of Metallurgy and Materials Engineering.

\section{Introduction}

Fuel cells are considered the ideal solution to overcome several problems such as pollution, depletion of energy resources and market fluctuations arising due to the exploitation of fossil fuels. The successful implementation of a 'hydrogen economy' depends on various technical and economic aspects and requires a rigorous materials selection through an iterative design process [1]. Among the various types of fuel cells, proton exchange membrane fuel cells (PEMFCs) have reached grid parity with conventional power-generating technologies [2], in particular for transportation, as illustrated by the increasing number of fuel cell vehicles and their predicted commercialisation [3]. 
In a typical proton exchange membrane fuel cell (PEMFC), the iterative design process starts with optimisation of the proton exchange membrane, the performancelimiting component, which plays a dual role - as an ionic conductor between the anode and the cathode - and as an electronic insulator between the electrodes to facilitate electron flow through an external electronic circuit [4]. However, the state-of-the-art PEMFCs still fall short of the desired targets in performance, durability, and in particular, the operational temperature range [5]. Table 1 [6] lists the 2015 US DOE targets for high temperature PEM materials. These targets cover the most crucial properties - proton conductivity, thermal, mechanical and chemical stability, durability, compatibility with other fuel cell components and eco-friendly nature.

Table 1 Targets for proton exchange membranes for transport application

\begin{tabular}{ll}
\hline Characteristic & 2015 Target \\
Maximum operating temperature & $120^{\circ} \mathrm{C}$ \\
Unassisted start up from temperature & $-40^{\circ} \mathrm{C}$ \\
Conductivity & $0.1 \mathrm{~S} \mathrm{~cm}^{-1}\left(120^{\circ} \mathrm{C}\right)$ \\
& $0.07 \mathrm{~S} \mathrm{~cm}^{-1}($ Ambient $)$ \\
& $0.01 \mathrm{~S} \mathrm{~cm}^{-1}\left(-20^{\circ} \mathrm{C}\right)$ \\
Area specific resistance & $0.02 \mathrm{\Omega} \mathrm{cm}^{2}$ \\
Relative humidity/inlet water vapour partial pressure & $50 \% / 1.5 \mathrm{kPa}$ \\
Hydrogen/oxygen crossover at 1 atm & $2 \mathrm{~mA} \mathrm{~cm}$ \\
Cost & $20 \mathrm{US} \$ \mathrm{~m}^{2}$ \\
Durability with cycling & $5000 \mathrm{~h}$ \\
\hline
\end{tabular}

Several attempts are underway to meet these targets and to develop alternative membranes that perform better than Nafion - the industrial benchmark - especially at higher temperatures $\left(T>100^{\circ} \mathrm{C}\right)$. Fuel cells with working temperatures of $120-130^{\circ} \mathrm{C}$ are much desired as they could drastically reduce or eliminate the $\mathrm{CO}$ poisoning of the $\mathrm{Pt}$ catalyst and even allow platinum to be replaced by cheaper catalysts [7].

The common methods in this regard include acid-base blending [8-10], thermal annealing [11], addition of inorganic fillers in organic polymer matrices [12] and incorporation of ion-rich species such as ionic liquids in the polymer membrane [13,14]. Among these methods, organic-inorganic composites are the most promising, as they combine the proton conductivity of the polymer and the water retention properties of the filler even at high temperature and low humidity conditions. To reinforce the number of charge carriers that contribute to the total conductivity, the filler can also be functionalised with protonic functional groups.

In this study, we have explored the effects of the silica functionalisation route on the thermal, mechanical and structural properties of SPEEK-silica composite membranes. The motivation of choosing SPEEK as the host polymer lies in the fact that it is the most promising low cost alternative for Nafion, especially in terms of thermal and mechanical stability. The two-phase nanostructure of SPEEK comprising a hydrophobic backbone and hydrophilic ionic domains consisting of sulfonic acid groups is a canonical example of sulfonated ionomers. This biphasic structure contributes to enhanced thermal and mechanical properties that favour the fabrication of membranes with high degrees of sulfonation and hence proton conductivity comparable to that of Nafion $[14,15]$. 
In addition to PEMFC applications, SPEEK has been extensively studied for direct methanol fuel cells (DMFCs) due to its less pronounced hydrophilic/hydrophobic separation compared to Nafion [16]. This results in low electro-osmotic drag and hence lower methanol crossover, a highly desired property for DMFC applications. Although a high degree of sulfonation results in a high proton conductivity value, it generally affects the dimensional stability and the swelling behaviour of the membranes, as confirmed in our previous study [17]. For practical fuel cell applications, the dimensional stability must be enhanced by controlling the swelling behaviour of the membranes, while retaining high proton conductivity. To address this challenge, we have used silica, functionalised with sulfonic acid group, as the filler in the SPEEK membranes. It is expected that the incorporation of this hydrophilic inorganic filler will prevent or retard membrane dehydration, enhance the mechanical stability against the swelling/drying cycles in normal fuel cell conditions, and increase the number of available proton conduction pathways. The compatibility of the filler with the polymer matrix is also worth studying to establish the optimal composition and synthesis parameters required to fabricate thermo-mechanically stable composite membranes. Although there have been numerous reports on SPEEK-silica composite membranes, little attention has been paid to the effects of silica functionalisation parameters on the properties and performance of the resultant membranes.

For the first time, two different methods to add sulfonic acid groups to the silica nanoparticles - direct sulfonation and co-condensation (sol-gel) of organosilane precursors - are compared in terms of compatibility with a sulfonated ionomer matrix. We discuss the effects of the sulfonation route on the stability of polymer electrolyte membranes with the functionalised silica fillers. While the direct sulfonation method is based on the physical adsorption of the sulfonic acid group on the silica nanoparticles, the sol-gel method is based on the chemical attachment of the functional groups by the cocondensation of the organosilane precursors and subsequent oxidation. The results of this comparison are presented in terms of thermal analysis by combined thermogravimetry-differential scanning calorimetry (TGA-DSC), mechanical analysis by dynamic mechanical analysis (DMA), structural analysis by NMR, and water uptake measurements of the composite membranes.

\section{Experiment}

\subsection{SPEEK synthesis}

The PEEK polymer was sulfonated according to the procedure reported elsewhere $[17,18]$. Typically, $5 \mathrm{~g}$ of PEEK powder $\left(\right.$ VICTREX $^{\circledR}$ PEEK $^{\mathrm{TM}} 450 \mathrm{PF}$ ) was dried in a vacuum oven at $80^{\circ} \mathrm{C}$ prior to sulfonation. The dried powder was then added to $95 \mathrm{~mL}$ of concentrated sulphuric acid $\left(\mathrm{H}_{2} \mathrm{SO}_{4}, 95-98 \%\right.$, ACS $)$ very slowly to avoid coagulation, with continuous stirring in nitrogen atmosphere. SPEEK samples with three different degrees of sulfonation (DS) were prepared by varying the sulfonation temperature from room temperature to $60^{\circ} \mathrm{C}$ and the reaction time from $5 \mathrm{~h}$ to $72 \mathrm{~h}$. The initial concentration ratio of PEEK/ $\mathrm{H}_{2} \mathrm{SO}_{4}$ was maintained at $5 / 95(\mathrm{w} / \mathrm{v})$ in all the experiments. The sulfonated polymer (SPEEK) was slowly precipitated in ice-cold ultrapure water $(18.2 \mathrm{M} \Omega)$. The collected SPEEK strands were washed thoroughly with ultrapure water to remove excess acid until neutrality and then dried at $80^{\circ} \mathrm{C}$ for $12 \mathrm{~h}$ in a vacuum oven 
for the removal of moisture. Samples sulfonated at $60^{\circ} \mathrm{C}$ for more than $5 \mathrm{~h}$ exhibited excessive swelling and eventual dissolution in water, and are therefore not considered in this study. The DS values of the samples were determined by ${ }^{1} \mathrm{H}$ NMR spectroscopy, following the procedure reported by Xing et al. [19] from the ratio of the peak area of the distinct $\mathrm{H}_{13}$ signal to the integrated peak area of the signals corresponding to all the other hydrogens, as shown in Figure 1.

Figure 1 Chemical structure and nomenclature of aromatic protons for the SPEEK repeat unit<smiles>CC(C)(C)Oc1ccc(OC2CCC(C(=O)C3CCC(C(C)(C)C4CCC(C(O)C5CCC(C(O)C6CCC(C(C)(C)C)CC6)CC5)CC4)CC3)CC2)cc1</smiles>

\subsection{Silica functionalisation}

Method 1: Sol-gel (Co-condensation) - 3-mercaptopropyltrimethoxysilane (MPTMS) was used as the organosilane precursor to prepare the functionalised silica through co-condensation method [20]. In a typical experiment, MPTMS was added dropwise to $2 \mathrm{~g}$ of fumed silica so that all the liquid was adsorbed by the silica. After a reaction time of $24 \mathrm{~h}$ at room temperature, the modified silica was oxidised with $32 \mathrm{~mL}$ of a $33 \% \mathrm{H}_{2} \mathrm{O}_{2}$ solution and the suspension was stirred for $1 \mathrm{~h}$ at $60^{\circ} \mathrm{C}$. The solid phase was extracted from the mixture by centrifugation at $2500 \mathrm{rpm}$ for $10 \mathrm{~min}$, and then washed with ultrapure water. The extracted solid was then suspended in a $10 \mathrm{wt} \% \mathrm{H}_{2} \mathrm{SO}_{4}$ solution for $1 \mathrm{~h}$ and washed as before. The sulfonic acid functionalised silica was obtained as the final product after drying the solid at $60^{\circ} \mathrm{C}$ for $24 \mathrm{~h}$ in a vacuum oven. A schematic timeline of steps performed in this method has been presented in Figure 2.

Figure 2 Timeline of steps in sol-gel method of silica functionalisation (see online version for colours)

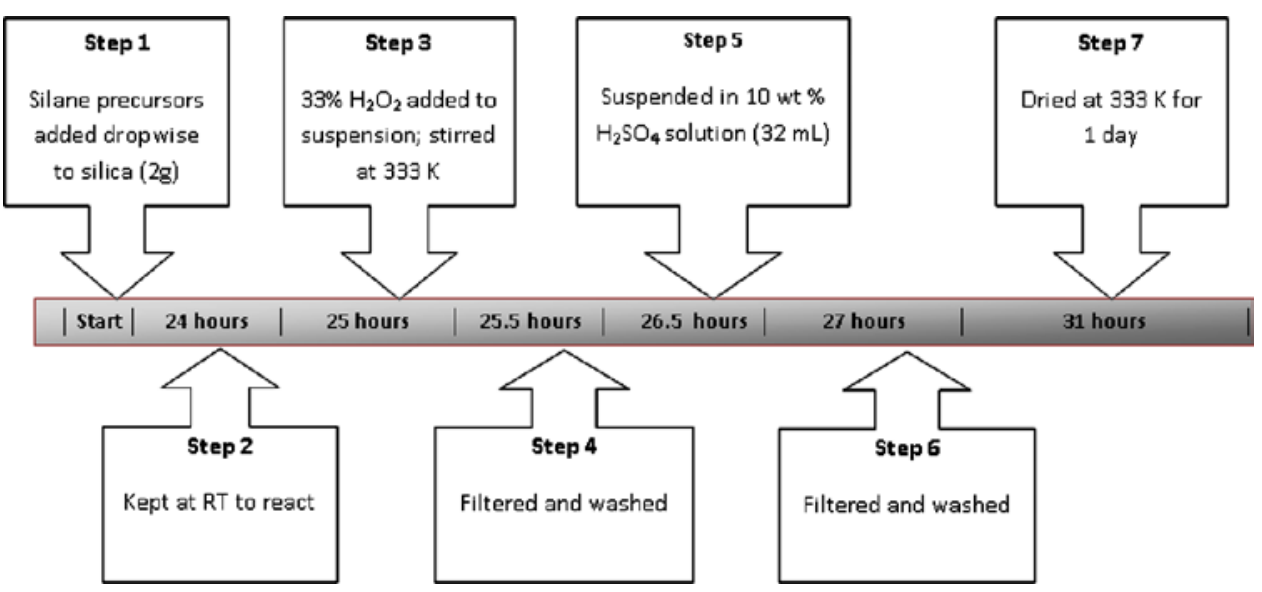

Method 2: Direct sulfonation - In this method, the silica particles were functionalised with sulfonic acid groups according to the procedure reported elsewhere [21]. The functionalisation primarily occurs through the physical adsorption of the sulfonic acid groups by the silica surface. In a typical experiment, a $500 \mathrm{~mL}$ suction flask was 
loaded with fumed silica. Concentrated chlorosulfonic acid from a constant-pressure dropping funnel was added dropwise to the silica over a period of $30 \mathrm{~min}$ at room temperature. The mixture was vigorously stirred for $30 \mathrm{~min}$ for uniform adsorption and then obtained as the functionalised silica particles. The reaction involved in this method is represented as:

$$
\mathrm{SiO}_{2}-\mathrm{OH}+\mathrm{HSO}_{3} \mathrm{Cl} \rightarrow \mathrm{SiO}_{2}-\mathrm{OHSO}_{3}+\mathrm{HCl} \uparrow
$$

\subsection{Membrane fabrication and sample description}

The SPEEK sample was dispersed in N,N-dimethylacetamide (DMAc) at room temperature to make a $10 \mathrm{wt} \%$ solution. After the complete dissolution of SPEEK, the calculated amount (in weight percentage) of functionalised silica was dispersed in the polymer solution under continued stirring, followed by ultrasonication for $30 \mathrm{~min}$. The mixture was then cast onto a glass petri-dish and dried at $80^{\circ} \mathrm{C}$ in a vacuum oven for solvent evaporation. After $24 \mathrm{~h}$, SPEEK membranes of about $150 \mu \mathrm{m}$ thickness with uniformly dispersed silica were obtained. Although the initial silica content varied from $3 \mathrm{wt} \%$ to $15 \mathrm{wt} \%$, only results corresponding to the samples with $7 \mathrm{wt} \%$ and $10 \mathrm{wt} \%$ are discussed here. The samples with silica composition less than $7 \mathrm{wt} \%$ did not exhibit any significant deviations in properties from those of the pure samples, whereas membranes with more than $10 \mathrm{wt} \%$ silica were very brittle to be used in any meaningful fuel cell application.

The pure samples were labelled with their reaction temperature and duration. For example, the sample RT48 indicates that it was sulfonated at room temperature for $48 \mathrm{~h}$. The nomenclature of the composite samples follows the syntax Temp/Duration/ Sulfonation agent/Composition. For example, 605/CSA10\% refers to the sample sulfonated at $60^{\circ} \mathrm{C}$ for $5 \mathrm{~h}$ and functionalised with $10 \mathrm{wt} \%$ chlorosulfonic acid. Table 2 lists the samples studied in this work.

Table 2 Sample description with reaction conditions and silica composition

\begin{tabular}{lcccc}
\hline Sample code & \multicolumn{2}{c}{ Direct sulfonation } & \multicolumn{2}{c}{ Sol-gel method } \\
\hline Pure & 7 wt $\%$ silica & $10 \mathrm{wt} \%$ silica & 7 wt $\%$ silica & $10 \mathrm{wt} \%$ silica \\
RT48 & RT48/CSA7\% & RT48/CSA10\% & RT48/MPTMS7\% & RT48/MPTMS10\% \\
RT72 & RT72/CSA7\% & RT72/CSA10\% & RT72/MPTMS7\% & RT72/MPTMS10\% \\
605 & $605 /$ CSA7\% & $605 /$ CSA10 $\%$ & $605 / \mathrm{MPTMS7 \%}$ & $605 / \mathrm{MPTMS10} \%$ \\
\hline
\end{tabular}

\subsection{Characterisation}

The thermal properties of the samples were analysed using a Netzsch STA 449 F1 Simultaneous Thermal Analyser. The samples $(\sim 10 \mathrm{mg})$ were heated at a constant heating rate of $10^{\circ} \mathrm{C} / \mathrm{min}$ under constant nitrogen flow. The thermal behaviour of the samples by means of mass loss and differences in heat flow rate were simultaneously studied by thermogravimetric analysis (TGA) and differential scanning calorimetry (DSC), respectively. Dynamic mechanical analysis (DMA) was performed in the tension mode over a temperature range of $-20^{\circ} \mathrm{C}$ to $250^{\circ} \mathrm{C}$ in air on a Q800 DMA dynamic mechanical analyser (TA Instruments). A fixed frequency of $1 \mathrm{~Hz}$ was maintained during the 
measurements. The storage modulus (E'), loss modulus (E'), stress, strain and damping (tan delta) values as functions of temperature were obtained at a constant heating rate of $3 \mathrm{~K} / \mathrm{min}$

${ }^{1} \mathrm{H}$ solution NMR experiments were carried out on a Bruker AV 300 spectrometer at a ${ }^{1} \mathrm{H}$ Larmor frequency of $300.13 \mathrm{MHz}$ at room temperature. A $3 \mathrm{wt} \%$ solution of the polymer sample in deuterated dimethyl sulphoxide $\left(\mathrm{DMSO}-\mathrm{d}_{6}\right.$ ) was prepared for each analysis. The chemical shift of tetramethylsilane (TMS) was used as the internal standard reference. Water uptake values were determined by the percentage weight gain of wet membranes with respect to dried membranes. The membranes were dried in a vacuum oven at $120^{\circ} \mathrm{C}$ for $24 \mathrm{~h}$. Samples of dimension $20 \mathrm{~mm} \times 20 \mathrm{~mm}$ were immersed in deionised water at room temperature for $24 \mathrm{~h}$ to allow the saturation of the membranes. The surface of the wet membranes was gently wiped with tissue paper before weighing. The weight and the gain in length of the films were recorded. The percentage gain in the weight of the wet membrane compared to the dry membrane weight was recorded as water uptake. Each sample was tested with three specimens, and the results are the average of three test results.

\section{Results and discussion}

\subsection{Thermogravimetric analysis}

All the samples showed three-step thermal degradation patterns. In the thermograms shown in Figure 3, the initial weight loss observed around $100^{\circ} \mathrm{C}$ is attributed to the loss of absorbed moisture by the hygroscopic SPEEK molecules. This is confirmed by the observed increase of weight loss in the first step for the membranes with increasing DS, which is in good agreement with the water uptake values discussed later. The extension of this mass loss step up to about $150^{\circ} \mathrm{C}$ can be attributed to the removal of the residual solvent used to cast the SPEEK membranes [11]. In the composite membranes, the relatively higher mass loss observed in the temperature range $150-250^{\circ} \mathrm{C}$ than in the $50-150^{\circ} \mathrm{C}$ range can be attributed to the presence of excess water chemically retained by the functionalised silica particles.

The second step of degradation corresponds to the degradation of aromatic sulphonyl groups $\left(4\left(\mathrm{SO}_{3} \mathrm{H}\right) \rightarrow 4 \mathrm{SO}_{2} \uparrow+2 \mathrm{H}_{2} \mathrm{O} \uparrow+\mathrm{O}_{2} \uparrow\right)$. The onset temperature of this degradation is critical, because it represents the point at which the sulfonic acid chains responsible for proton conductivity start to break down. The thermograms in Figure 3 indicate better thermal stability of the composite membranes - with a minimum onset of degradation temperature at $280^{\circ} \mathrm{C}$ - compared to that of pure SPEEK membrane with an early degradation onset temperature of $200^{\circ} \mathrm{C}$. A progressive deterioration of thermal stability of the membranes with increasing DS is observed, which indicates the vulnerability of the sulfonic acid chains against such high temperatures. The third weight loss step is attributed to the decomposition of the main chain of PEEK in the range of $400-580^{\circ} \mathrm{C}$, which is caused by the catalytic degradation of the polymer chain by the $\mathrm{SO}_{3} \mathrm{H}$ functional groups [22]. 
Figure 3 TGA thermograms of pure and composite SPEEK membranes

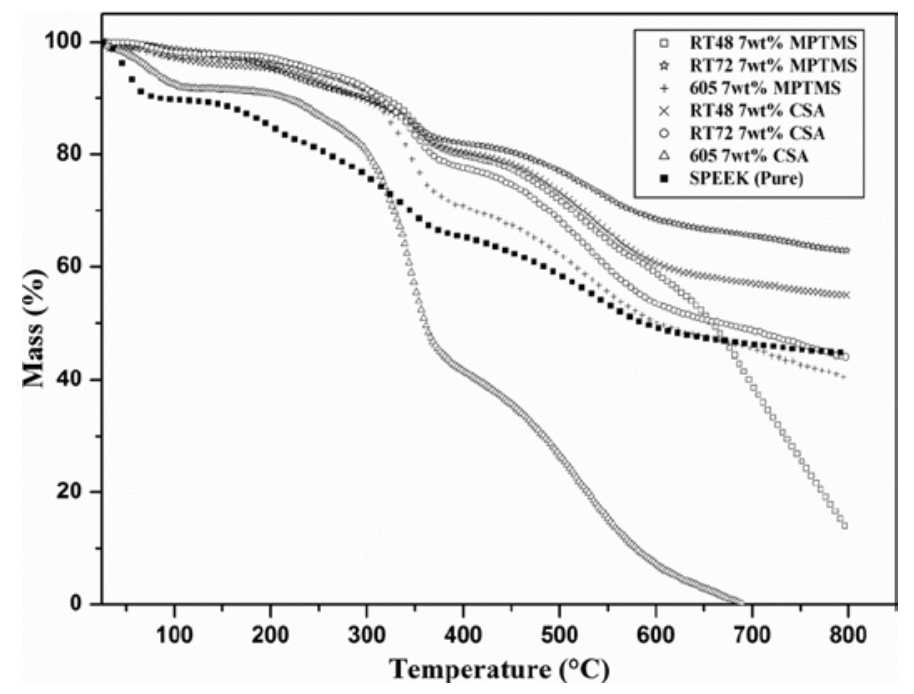

The onset of this degradation step also occurs at higher temperatures in the composite membranes than in pure SPEEK membranes, confirming enhanced thermal stability of the composite membranes. Among the composite membranes, the RT72/MPTMS7\% and RT72/CSA7\% samples exhibited the best thermal stability owing to their relatively lower mass loss of 18.45 and $22.87 \%$, respectively, in the sulfonic acid degradation step. The sol-gel prepared RT72/MPTMS7\% sample was thermally superior to its CSA counterpart as indicated by its slower degradation of the main chain and the corresponding mass loss of $13 \%$, compared to the rapid main chain decomposition of the RT72/CSA7\% sample with a corresponding mass loss of $23 \%$. This difference could be attributed to the relatively higher DS value of the directly sulfonated sample, as confirmed by NMR analysis.

The maximum mass loss temperatures in each of the three steps can be deduced from the differential thermograms (DTG), as shown in Figure 4. The DTG of the pure SPEEK membrane revealed a two-step degradation of sulfonic acid groups - at $193^{\circ} \mathrm{C}$ and $330^{\circ} \mathrm{C}$ - due to the structural reorganisation within the polymer chain caused by the heat flow. On the other hand, the degradation of sulfonic acid groups in the composite membranes started at relatively higher temperatures, ranging from $204^{\circ} \mathrm{C}$ to $345^{\circ} \mathrm{C}$, with an increasing trend with the degree of sulfonation. This enhanced rigidity of the polymer chain with increasing DS was also confirmed by DSC analysis.

Figure 5 represents the DSC curves of the pure and composite membranes. The temperature range of DSC analysis was set between room temperature and $320^{\circ} \mathrm{C}$, as the DTG profiles revealed the onset of sulfonic acid group decomposition at around $320^{\circ} \mathrm{C}$ irrespective of the degree of sulfonation. The DSC scans of all the samples showed broad endothermic signals with peaks centred in the range of $50-70^{\circ} \mathrm{C}$. These endothermic peaks correspond to the initial loss of moisture from the membranes. 
Figure 4 Differential thermograms (DTG) of pure and composite SPEEK membranes

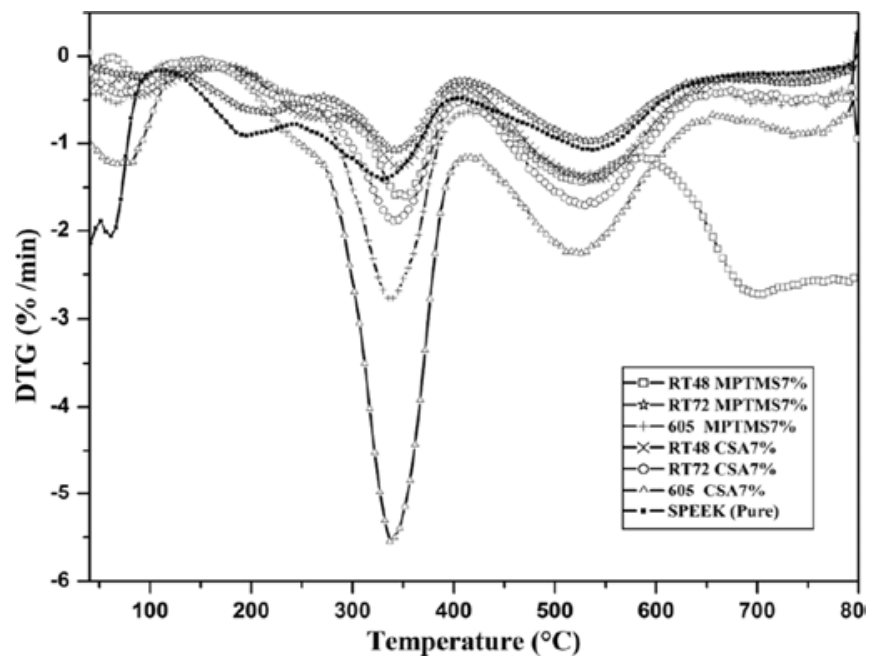

Figure 5 DSC scans of pure and composite SPEEK membranes

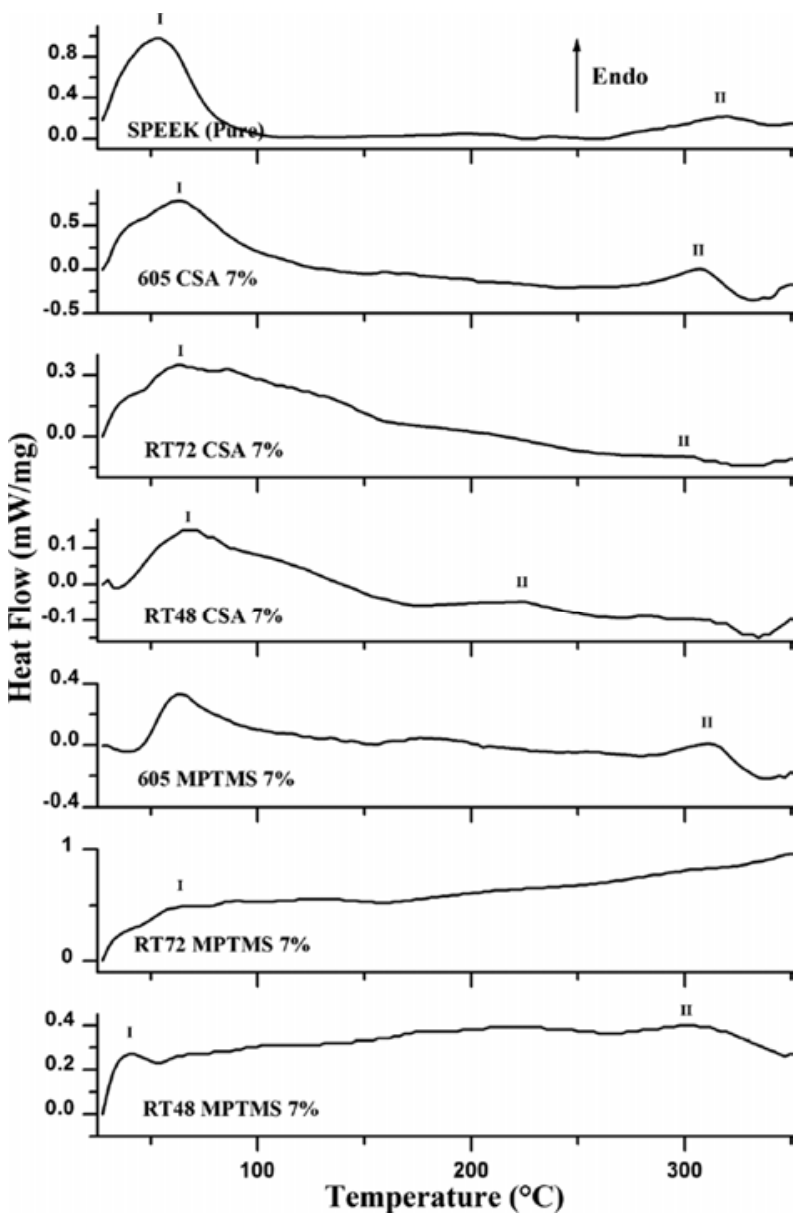


Carbone et al. [23] in their remarkable study of the thermal and structural properties of SPEEK suggest that the immediate onset of these transitions with heat flow is characteristic of sulfonated ionomers exhibiting a rather complicated water distribution. It was observed that the intensity of these peaks increased with the increase in the sulfonation degree, as more water molecules are attached to the additional sulfonic acid groups, which is also confirmed by the water uptake profiles as function of the sulfonation degree. The presence of the sulfonic acid groups increases the electrostatic interactions between polymer chains, resulting in an increase of residual stress present within the nanodomains of the SPEEK membranes [24]. These endothermic peaks could also be assigned to the relaxation of the amorphous regions in the SPEEK, marking the 'order-disorder' structural reorganisation within the ionic clusters [25].

Hence, these peaks can be collectively assigned to the melting of the PEEK nanodomains and the simultaneous evaporation of water tightly bound to these domains [24]. The higher evaporation temperature in the case of the composite membranes was thus due to the presence of strong interactions of the water molecules with the sulfonic acid groups and the silica particles. A second endothermic peak, relatively smaller than the first peak, was observed for all the samples around $320^{\circ} \mathrm{C}$. This peak is associated with the softening or the structural reorganisation of semi-crystalline SPEEK polymer microdomains, whose average size decreases with increasing DS [26].

Another interesting transition in these materials occurs at an intermediate temperature - the glass transition temperature $\left(T_{g}\right)$ - showing a relaxation behaviour that is observed to shift upwards with increasing DS value. To calculate the $T_{g}$ values, the DSC curves were differentiated with respect to time. In Figure 6, the minima of the differentiated DSC (DDSC) curves give the $T_{g}$ value of the samples, which are presented in Table 3 along with the $T_{g}$ values measured by DMA technique.

The $T_{g}$ values of the SPEEK-silica composite membranes are higher than that of pure SPEEK membranes by more than at least $50^{\circ} \mathrm{C}$ and increased with increasing DS. The enhancement of $T_{g}$ in the composite membranes may be attributed to the combined effect of the water molecules associated with the sulfonic acid groups and silicon oxide [27]. Another factor responsible for this tendency could be the strong interaction between sulfonic acid groups in SPEEK and the modified silica. The incorporation of sulfonic acid groups in the phenyl rings between the two ether oxygens enhances the rigidity of the polymer, as they form strong hydrogen bonds with other sulfonic groups or with the ketone groups of the polymer backbone [23]. As $T_{g}$ reflects the polymer chain mobility, the narrow distribution of the $T_{g}$ values $\left(\sim 30^{\circ} \mathrm{C}\right.$ range $)$ observed in the composite membranes may be attributed to the saturation of the effective interaction between the sulfonic acid groups above a certain DS value. These observations are consistent with the dynamic mechanical analysis, confirming the increased thermal stability of the composite membranes. Among the composite membranes, the sol-gel prepared MPTMS membranes were thermally more stable than the CSA membranes, as implied by the higher onset temperature corresponding to the main polymer chain degradation.

\subsection{Dynamic mechanical analysis}

DMA can be used as a complementary tool along with DSC to determine the $T_{g}$ and the useful operational temperature range of a polymer membrane in applications such as PEMFCs. Moreover, DMA of a polymer provides specific details about the glassy 
nature of the polymer at low temperatures, the viscous behaviour above $T_{g}$ and the viscoelastic characteristics at intermediate temperatures [28]. These remarkable changes in viscoelastic properties arise due to molecular motions and segmental mobility of the polymer chain.

Figure 6 First derivative curves of the DSC scans of pure and composite SPEEK membranes

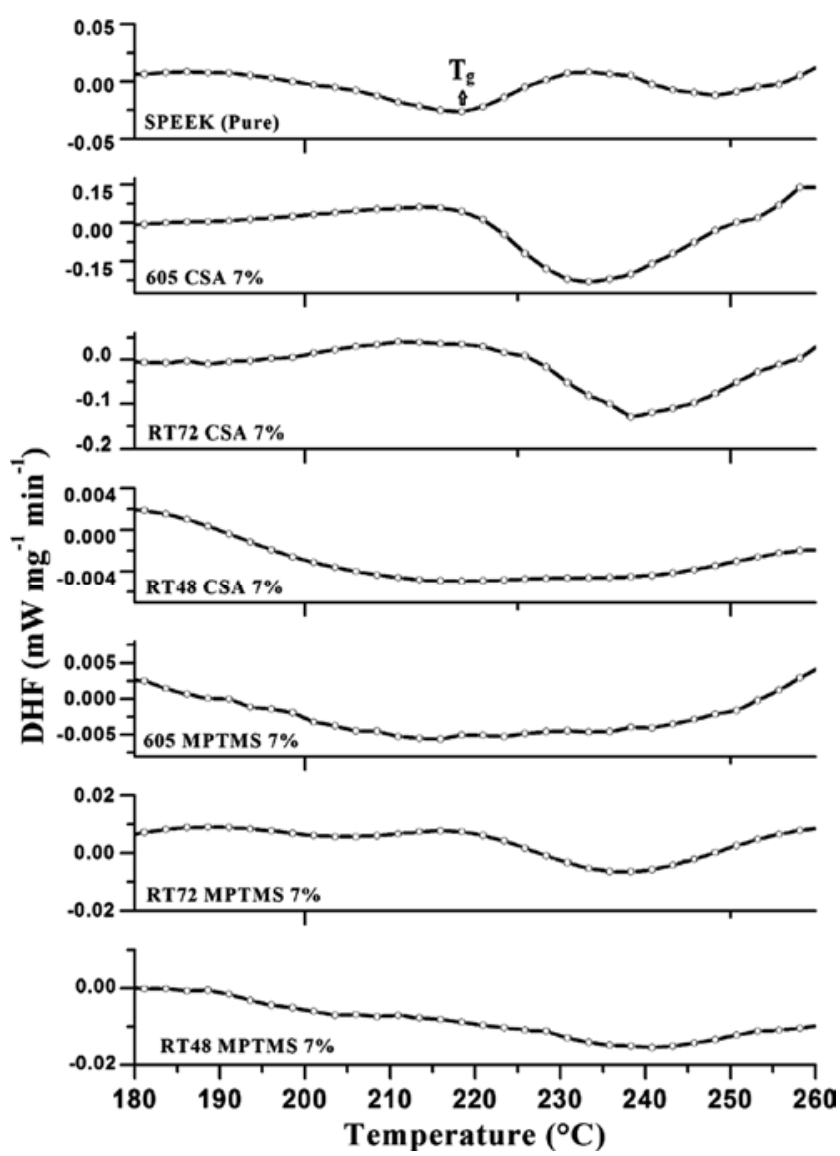

Table 3 Glass transition temperature values determined by DSC and DMA techniques

\begin{tabular}{lll}
\hline Sample & \multicolumn{1}{c}{$\mathrm{Tg}^{a}$} & \multicolumn{1}{c}{$\mathrm{Tg}^{b}$} \\
\hline SPEEK (pure) & 218.10 & 208.12 \\
RT48 MPTMS 7\% & 240.86 & 222.12 \\
RT72 MPTMS 7\% & 238.19 & 200.71 \\
605 MPTMS 7\% & 214.1 & 216 \\
RT48 CSA 7\% & 215.82 & 170.13 \\
RT72 CSA 7\% & 238.19 & 192 \\
605 CSA 7\% & 233.22 & 188.13 \\
\hline
\end{tabular}

${ }^{\mathrm{a}} T_{g}$ values calculated by DSC; ${ }^{\mathrm{b}} T_{g}$ values calculated by DMA. 
Figure 7(a) and (b) shows the DMA curves of the samples studied. The slight increase of storage modulus (E') up to about $100^{\circ} \mathrm{C}$ corresponds to the removal of residual casting solvent (DMAc) and water, which have a plasticising effect on the membranes. This is followed by a Hookean behaviour corresponding to the gamma transitions arising due to the bending and stretching of hydrogen bonds in the polymer chain, and then by a beta transition arising due to the motion of the side chains. At this stage, structural rearrangements occur in the molecules through a relaxation mechanism until sufficient mobility is obtained at the glass transition temperature to allow the chains to move to a lower energy state [29]. The storage moduli of the SPEEK/MPTMS membranes were comparable to that of pure SPEEK membranes and showed an increasing trend with increasing DS as shown in Figure 7(a). In particular, the storage modulus of the SPEEK605/MPTMS10\% sample was higher than that of pure SPEEK. On the contrary, storage moduli of the SPEEK/CSA membranes were lower than that of pure SPEEK membranes, and further decreased with increasing DS, as shown in Figure 7(b). This might be due to the better coordination of the sol-gel route silica with the SPEEK polymer matrix compared to that of directly sulfonated silica.

Figure 7 Storage modulus of (a) pure and sol-gel prepared SPEEK membranes and (b) directly sulfonated silica membranes as a function of temperature
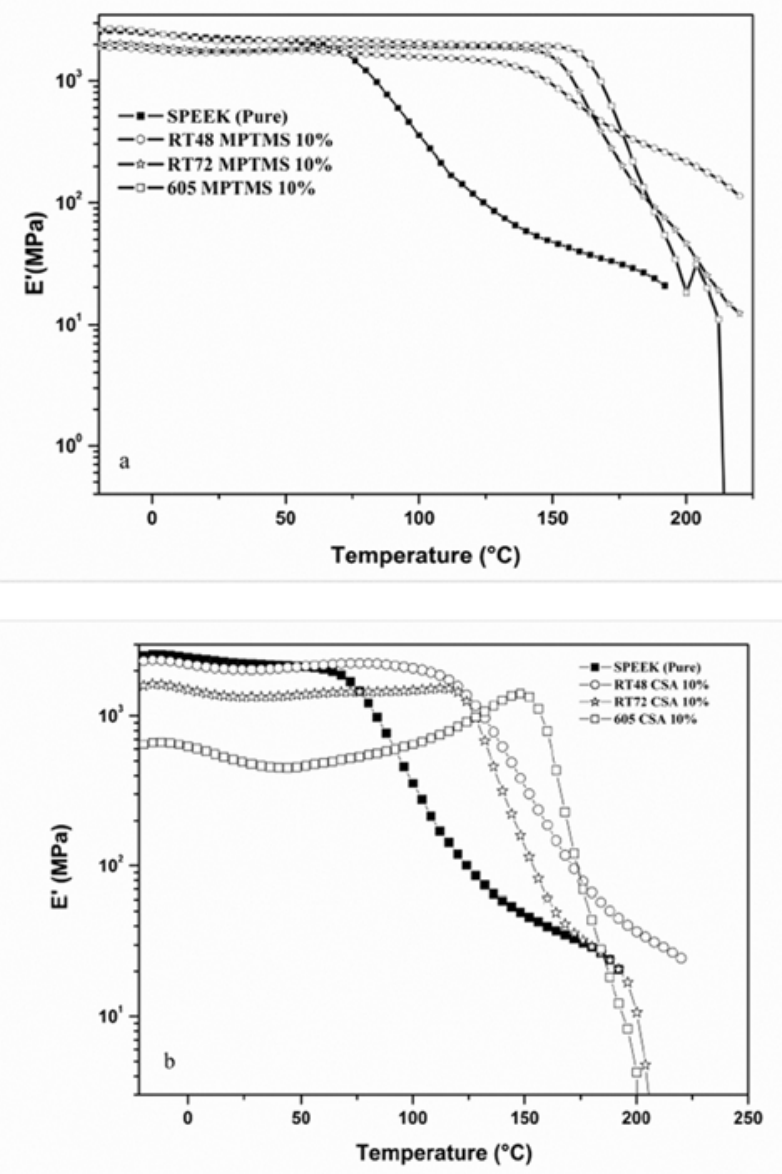
Figure 8(a)-(c) shows a direct comparison of the storage moduli of the membranes prepared by the sol-gel and direct sulfonation method at different DS levels. Although the storage modulus of the RT48/MPTMS sample was slightly lower than that of RT48/CSA, the trend reversed at higher DS values. This confirms that better mechanical strength could be achieved with silica prepared by sol-gel route in spite of high DS values.

Figure 8 Comparison of storage moduli of (a) RT48, (b) RT72, and (c) 605 sol-gel and directly sulfonated membranes

a

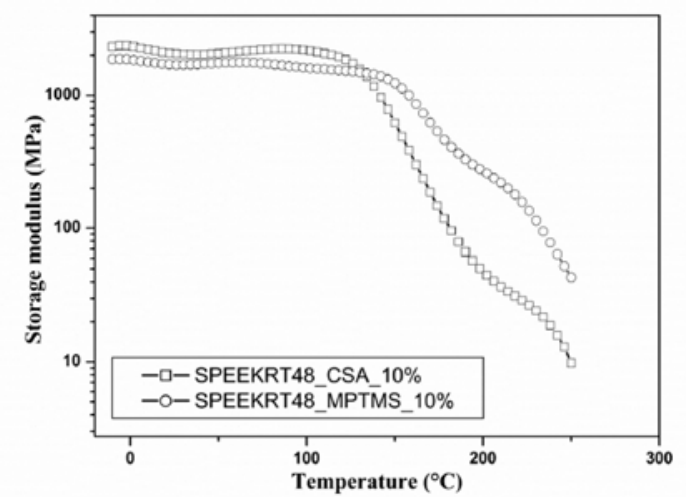

b
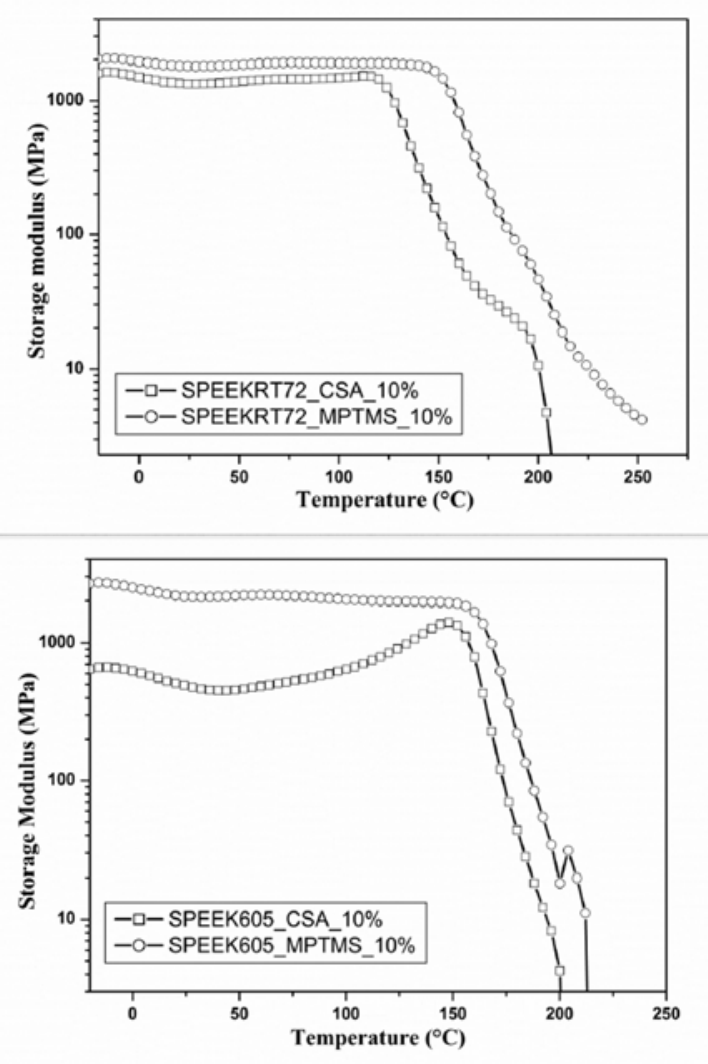
The primary (alpha) transition due to the motion of main chain of the SPEEK polymer is marked by the sharp fall in the storage modulus. Hence, from the onset point of this alpha transition, the glass transition temperature of the membranes can be determined, which is also reflected by the alpha peak in the $\tan \delta$ curve [30] illustrated in Figure 9(a)-(c).

Figure 9 Tan $\delta$ profiles of (a) RT48, (b) RT72, and (c) 605 sol-gel and directly sulfonated membranes

a

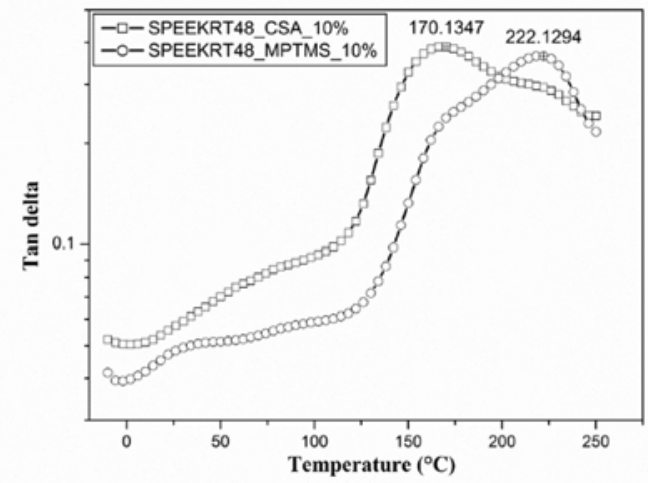

b

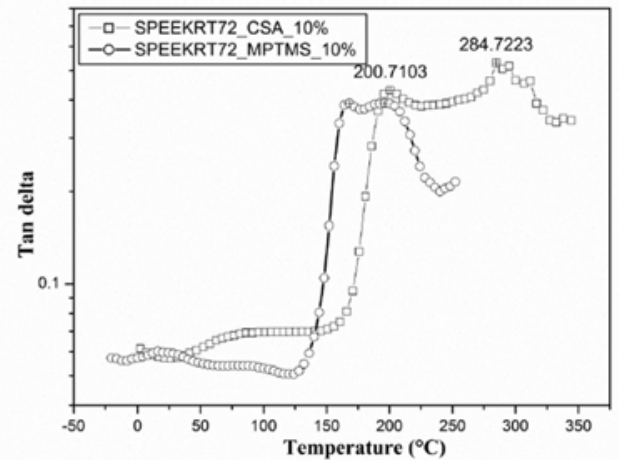

c

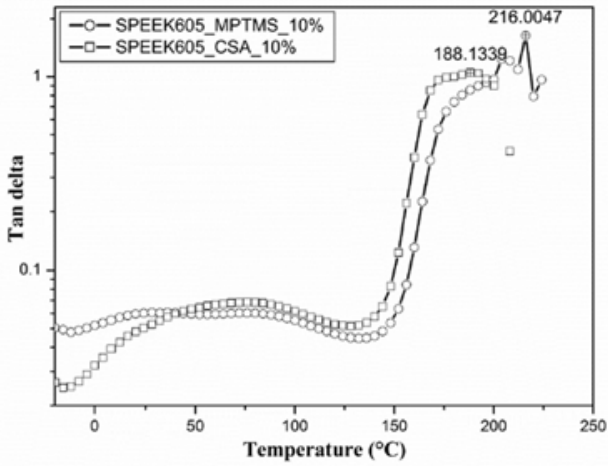


The $\tan \delta$ profiles (Figure 9(a)-(c)) show the remarkable increase of glass transition temperature up to $285^{\circ} \mathrm{C}(\mathrm{DS}=0.81)$ for the SPEEK/MPTMS membranes (Figure 9(b)). These improvements again validate the suitability of the composite membranes for intermediate temperature fuel cell applications. The $T_{g}$ values of the samples with $7 \mathrm{wt} \%$ silica are also compared with the values determined from DSC analysis in Table 3 . From these values, it is clear that the $T_{g}$ and hence the operating temperature of the membranes can easily be increased by $20^{\circ} \mathrm{C}$ by incorporation of sulfonated silica.

On further heat treatment above the $T_{g}$, the polymer chains of the semi-crystalline SPEEK polymer gain enough mobility and reorganise into crystallites. This is reflected as the second peak in the $\tan \delta$ curves. This transition, referred to as the $T_{\alpha}^{*}$ transition, extends the operating range of a material above the $T_{g}$ and depends on the processing parameters such as the thermal treatment history and physical aging [29]. A second peak $\left(T_{\alpha}^{*}\right)$ was observed in the DMA analysis of the RT72/MPTMS and RT72/CSA samples (Figure $9(\mathrm{~b})$ ) at temperatures $50-80^{\circ} \mathrm{C}$ above the corresponding $T_{g}$ values, respectively. This indicates their enhanced mechanical properties due to the incorporation of the silica filler particles, and suggests that these membranes can be used up to at least $50^{\circ} \mathrm{C}$ above their $T_{g}$ values, which is a significant improvement in a PEMFC membrane in terms of mechanical stability.

\subsection{Nuclear magnetic resonance}

The ${ }^{1} \mathrm{H}$ NMR peaks of the low DS samples were broad and unresolved due to the slower molecular motions of the polymer in solution resulting from the lower solvation of the polymer molecules at lower sulfonation levels [31]. Figures 10 and 11 show the ${ }^{1} \mathrm{H}-\mathrm{NMR}$ spectra of the pure and composite SPEEK samples, respectively, and the peaks were assigned according to the literature [32]. The ${ }^{1} \mathrm{H}$ NMR peaks in the range of 6.5-8.0 ppm are due to the aromatic protons in the SPEEK polymer. This confirms the sulfonation of the PEEK polymer with the sulfonic acid group along the side chain. The observation of broad peaks in the region between $8 \mathrm{ppm}$ and $8.5 \mathrm{ppm}$, especially in the highly sulfonated samples, can be assigned to the interaction between the sulfonic acid hydrogen atoms and the residual DMAc solvent used to cast the membranes. These weak signals arise due to the resonance of the electron-depleted hydrogen atoms at a relatively low field [32].

The electrophilic substitution reaction of the PEEK polymer in sulphuric acid results in the incorporation of sulfonic groups into the hydroquinone segment of the polymer chain. These sulfonic acid groups in the SPEEK repeat unit increase the deshielding effect for the proton $\mathrm{H}_{13}$ (shown in Figure 1), causing the $\mathrm{H}_{13}$ resonance to move to a higher chemical shift compared to the protons $\mathrm{H}_{14}$ and $\mathrm{H}_{15}$. Therefore, a distinct signal for $\mathrm{H}_{13}$ can be observed from the NMR spectra. The highly mobile sulfonic acid proton makes it impossible to directly obtain ${ }^{1} \mathrm{H}$ NMR signal for the sulfonic acid. Nevertheless, the number of the $\mathrm{H}_{13}$ proton is exactly equal to that of the sulfonic acid protons, making the estimation of the sulfonation degree easier [32]. Hence, the $\mathrm{H}_{13}$ signal intensity may be used for the estimation of the $\mathrm{SO}_{3} \mathrm{H}$ group concentration or the degree of sulfonation (DS) per repeat unit. The DS value can be calculated as a ratio of sulfonated units to total units as follows [33] 


$$
\frac{n}{12-2 n}=\frac{\operatorname{Area}\left(\mathrm{H}_{13}\right)}{\text { Area }\left(\mathrm{H}_{\text {rest }}\right)} \quad(0 \leq n \leq 1)
$$

where $n$ is the number of $\mathrm{H}_{13}$ per repeat unit and $\mathrm{H}_{\text {rest }}$ correspond to all the hydrogens except $\mathrm{H}_{13}$, from which the DS value can be derived as

$$
\mathrm{DS}=n \times 100 \%
$$

The chemical shift assignments of ${ }^{1} \mathrm{H}$ NMR spectra for the RT72 and RT72/MPTMS7\% samples are listed in Table 4.

The DS values of the samples calculated by the relative integration of the $\mathrm{H}_{13}$ peak from ${ }^{1} \mathrm{H}$ NMR analysis are listed in Table 5. The DS values increased with increasing sulfonation time and reaction temperature.

With respect to the synthesis route, the NMR analysis revealed that the DS values of the samples increased in the order Pure $<$ Sol-gel $<$ Direct sulfonation. In spite of the relatively poor coordination of the sulfonic acid groups with the polymer in the directly sulfonated samples, the overall amount of sulfonic acid was higher than in the sol-gel samples. These loosely bound sulfonic acid groups could contribute to the relatively higher water uptake leading to lower hydrolytic stability and mechanical strength as observed in the water uptake and DMA measurements, respectively.

Figure10 ${ }^{1} \mathrm{H}$ NMR spectra of pure SPEEK samples

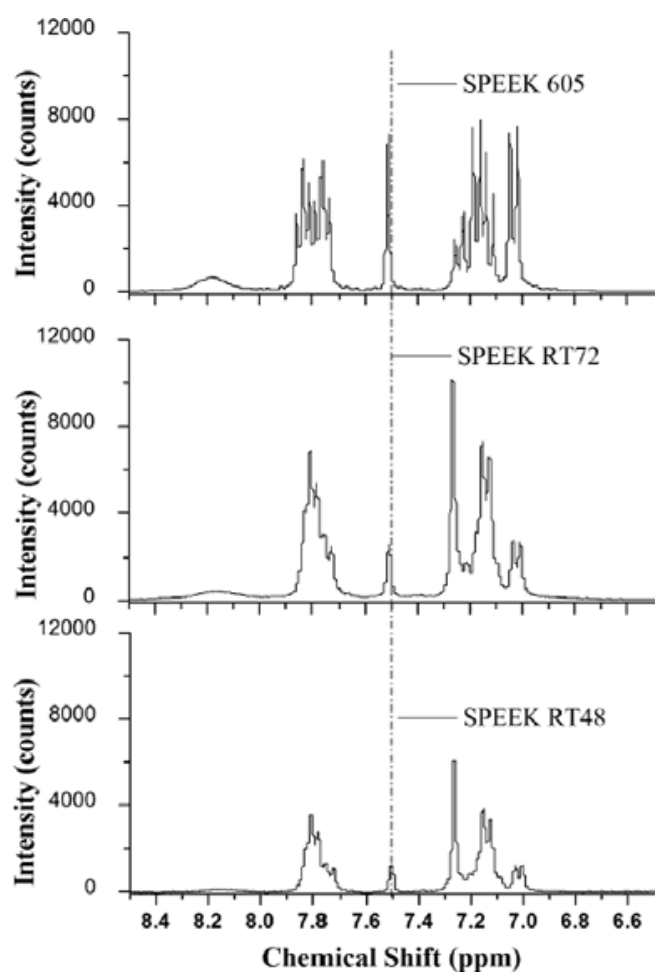


Figure $11{ }^{1} \mathrm{H}$ NMR spectra of composite SPEEK samples

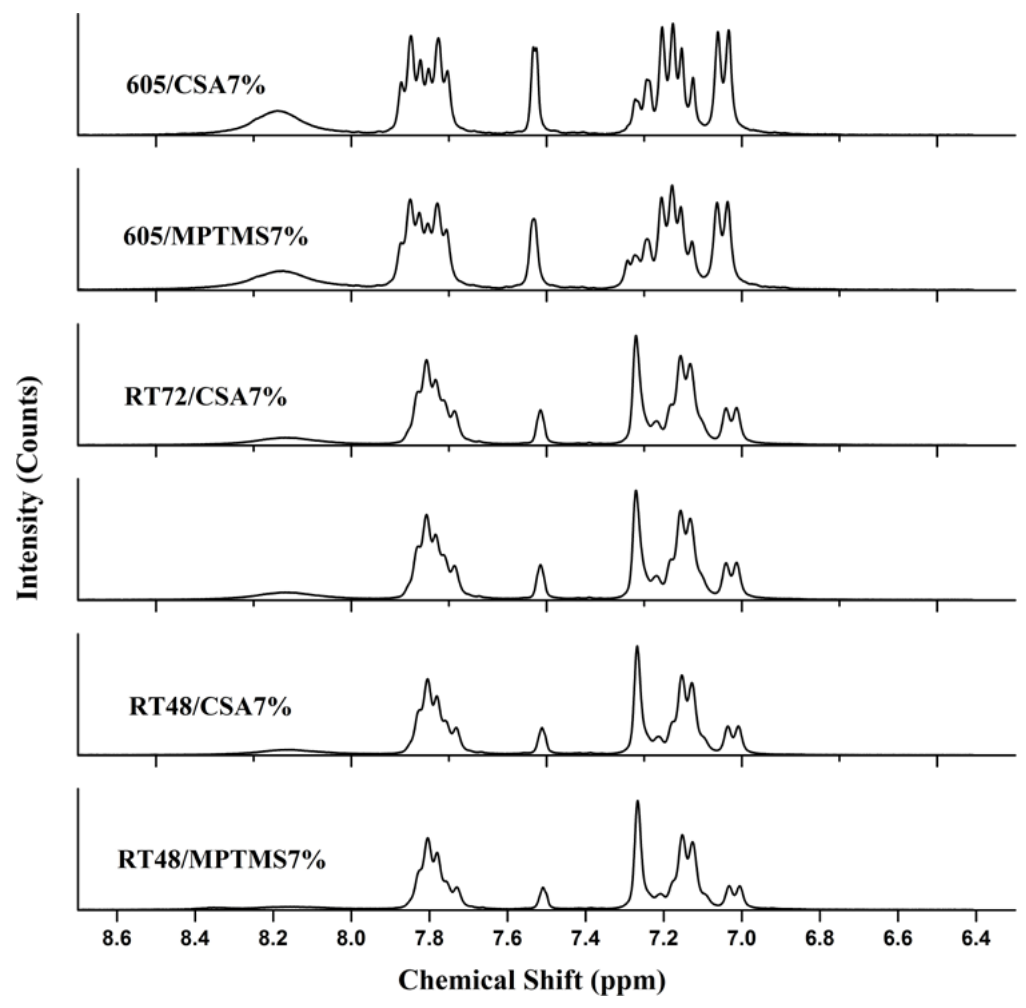

Table 4 The chemical shift assignments of ${ }^{1} \mathrm{H}$ NMR spectra for the RT72 pure and sol-gel functionalised samples

\begin{tabular}{lcccccc}
\hline & \multicolumn{3}{c}{$\delta(\mathrm{ppm})$} & & \multicolumn{2}{c}{$\delta(\mathrm{ppm})$} \\
\cline { 2 - 3 } \cline { 6 - 7 } $\begin{array}{l}\text { Proton } \\
\text { designation }\end{array}$ & RT72 & RT72/ & Proton & & RT72/ \\
\hline 13 & 7.503 & 7.5147 & 9 & 7.7897 & 7.7836 \\
$1,2,3,4$ & $7.2681-7.2463$ & $7.2701-7.2538$ & 10 & 7.7843 & 7.7843 \\
5 & 7.1558 & 7.1558 & 11 & 7.0301 & 7.0393 \\
6 & 7.1325 & 7.1313 & & 12 & 7.0049 & 7.0126 \\
7 & 7.8078 & 7.8269 & & 14 & 7.2058 & 7.2173 \\
8 & 7.7956 & 7.8064 & 15 & 7.1012 & 7.0933 \\
\hline
\end{tabular}

Table 5 The DS values of the pure and composite samples calculated from ${ }^{1} \mathrm{H}$ NMR analysis

\begin{tabular}{lccc}
\hline & \multicolumn{3}{c}{ DS $(\%)$} \\
\cline { 2 - 4 } Sample & Pure & Sol-gel & CSA \\
\hline RT48 & 40.52 & 42.09 & 48.65 \\
RT72 & 49.04 & 51.54 & 55.90 \\
605 & 77.83 & 80.10 & 85.87 \\
\hline
\end{tabular}




\subsection{Water uptake}

Water uptake properties of sulfonated ionomers are critical in determining their intrinsic proton conductivity [34] and their dimensional stability. Proton transport in the membranes is facilitated by the dissociation of the acid groups by water molecules. In ionomers with low degrees of hydration ( $\lambda$, the number of water molecules per sulfonic acid group), proton conductivity is significantly reduced because of the less pronounced water percolation. This can also be attributed to the strong local retardation of the water diffusion resulting from the immobile sulfonic acid groups [35].

While proton transport is aided by water molecules, the hydration level must be controlled to prevent excessive swelling that can lead to mechanical instability of the membrane [36]. Thus, the swelling equilibrium in a membrane is attained by the balancing of opposing forces - the tendency of ionic clusters to surround themselves with water molecules and the resistance of the host polymer matrix to the uptake of more water [37]. Hence, the subsequent addition of sulfonic acid groups through sulfonation and then through the functionalised silica significantly increases the water retention properties of the SPEEK membranes. This explains the deterioration of the mechanical stability of the highly sulfonated SPEEK 605 membranes - as observed in the DMA curves - despite their higher degree of sulfonation and proton conductivity compared to the samples with lower DS. A large water uptake indicates the presence of ion-rich regions where the migration of protons involving species such as $\mathrm{H}_{3} \mathrm{O}$ and $\mathrm{H}_{2} \mathrm{O}_{5}$ needed for high proton conduction is enhanced [38].

Figure 12(a)-(c) shows the hydration number $(\lambda)$ values as a function of DS for the pure SPEEK, sol-gel functionalised and directly sulfonated SPEEK samples, respectively. The $\lambda$ value has an almost linear relationship with the degree of sulfonation. At higher degrees of sulfonation, the larger number of sulfonic acid ionic clusters dominates the water uptake mechanism, resulting in the apparently larger $\lambda$ values $-\mathrm{a}$ six-fold increase in the CSA membranes - and a three-fold increase in the case of the sol-gel prepared MPTMS membranes. This control of hydration number in spite of increased DS in the sol-gel prepared membranes again emphasises their relatively better mechanical properties over the CSA membranes.

\subsection{Sol-gel vs. direct sulfonation}

The overall superiority of the sol-gel synthesised membranes can be explained by the sulfonation mechanism involved during the incorporation of sulfonic acid groups on silica nanoparticles. The sol-gel process involved the quantitative incorporation of sulfonic acid functional groups on the pores of the silica particles. The two-step reaction started with the anchoring of thiol (-SH) groups through the addition of MPTMS, followed by the in-situ oxidation of these thiol groups by $\mathrm{H}_{2} \mathrm{O}_{2}$, resulting in the formation of the $\mathrm{SO}_{3} \mathrm{H}$ functional group with a high retention of sulphur and no loss of methyl groups [39]. These [ $\left.\mathrm{SO}_{3} \mathrm{H}\right]$-silica particles combine a high acidity and a good accessibility to the active centres, with larger channel diameters. Further, the treatment temperature of $60^{\circ} \mathrm{C}$ effectively reduces the leaching of sulphur by enhancing the extent of oxidation [20]. On the other hand, no attention has been paid to the oxidation mechanism in the direct sulfonation method. This could lead to the formation of undesired disulphide (S-S) groups, especially in samples with high sulphur loading. Although the physical adsorption method produced high fractions of $-\mathrm{SO}_{3} \mathrm{H}$ group, 
as indicated by the higher DS values than the pure and sol-gel prepared SPEEK membranes, the resultant membranes might not be capable of maintaining the long term stability of PEMs in typical PEMFC operating conditions.

Figure 12 Hydration number $(\lambda)$ and the corresponding DS values of (a) pure SPEEK, (b) sol-gel functionalised SPEEK, and (c) directly sulfonated SPEEK membranes (see online version for colours)
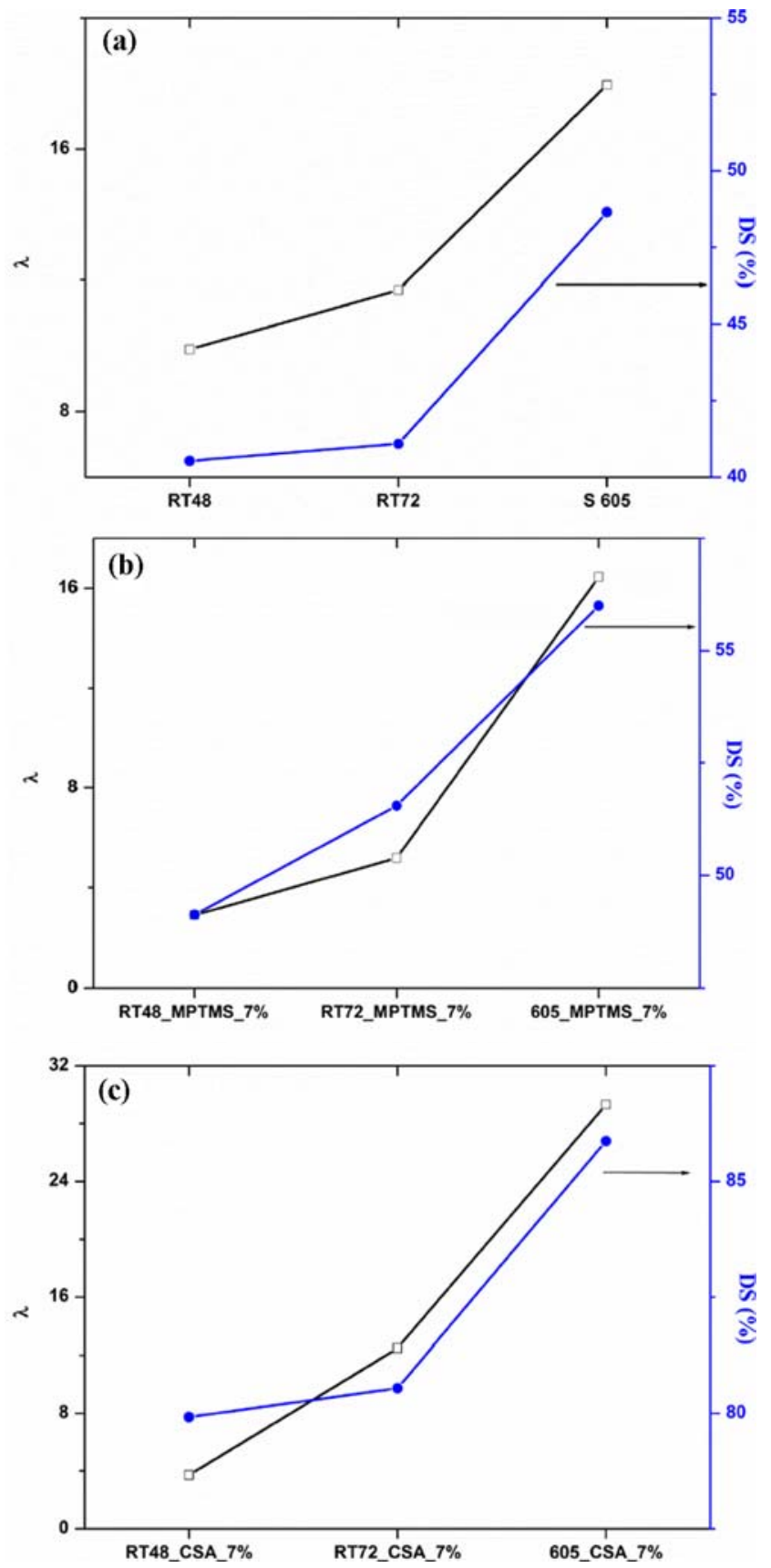


\section{Conclusion}

A comparative study of functionalisation of silica particles with sulfonic acid groups through sol-gel and direct sulfonation methods was conducted. The functionalised silica particles were used as fillers in sulfonated PEEK membranes. TGA and DMA studies showed that the thermal and mechanical properties of the $\mathrm{Si}\left[\mathrm{SO}_{3} \mathrm{H}\right]$-SPEEK membranes were better than those of pure SPEEK membranes. Among the composite membranes, the membranes with silica functionalised by sol-gel method were thermally and mechanically more stable than the directly sulfonated membranes by up to $100^{\circ} \mathrm{C}$, as indicated by the second degradation temperature and $T_{g}$ in the TGA thermograms and the DMA curves, respectively. Both types of composite membranes showed almost identical chain structure in ${ }^{1} \mathrm{H}$ NMR spectroscopy. Of the two methods investigated, the chemical modification of silica by sol-gel technique results in membranes with better thermal, mechanical and water uptake properties, highly desirable for typical fuel cell applications at higher temperature and lower relative humidity than in the state-of-the-art PEM fuel cells.

\section{References}

1 Steele, B.C.H. and Heinzel, A. (2001) 'Materials for fuel-cell technologies', Nature, Vol. 414, No. 6861, pp.345-352.

2 Carrette, L., Friedrich, K.A. and Stimming, U. (2001) 'Fuel cells - fundamentals and applications', Fuel Cells, Vol. 1, No. 1, pp.5-39.

3 The US Department of Energy (DOE) Fuel Cell Technologies Office Multi-Year Research, Development and Demonstration Plan - Fuel Cells (2011) http://www.eere.energy.gov/ hydrogenandfuelcells/mypp/pdfs/fuel_cells.pdf (Accessed 29 June, 2013).

4 Schmidt-Rohr, K and Chen, Q. (2008) 'Parallel cylindrical water nanochannels in Nafion fuel-cell membranes', Nat. Mater., Vol. 7, No. 1, pp.75-83.

5 Wieser, C. (2004) 'Novel polymer electrolyte membranes for automotive applications requirements and benefits', Fuel Cells, Vol. 4, pp.245-250.

6 Chandan, A., Hattenberger, M., El-Kharouf, A., Du, S., Dhir, A., Self, V. and Bujalski, W. (2013) 'High temperature (HT) polymer electrolyte membrane fuel cells (PEMFC) - a review', J. Power Sources, Vol. 231. pp.264-278.

7 Alberti, G. et al. (2001) 'Polymeric proton conducting membranes for medium temperature fuel cells $\left(110-160^{\circ} \mathrm{C}\right)$ ', J. Membr. Sci., Vol. 185, No. 1, pp.73-81.

8 Kerres, J., Ullrich, A., Meier, F. and Häring, T. (1999) 'Synthesis and characterization of novel acid-base polymer blends for application in membrane fuel cells', Solid State Ionics, Vol. 125, pp.243-249.

9 Pasupathi, S., Ji, S., Jan Bladergroen, B. and Linkov, V. (2008) 'High DMFC performance output using modified acid-base polymer blend', Int. J. Hydrogen Energy, Vol. 33, pp.3132-3136.

10 Zaidi, S.M.J. (2005) 'Preparation and characterization of composite membranes using blends of SPEEK/PBI with boron phosphate', Electrochim. Acta, Vol. 50, pp.4771-4777.

11 Knauth, P., Hou, H., Bloch, E., Sgreccia, E. and Di Vona, M.L. (2011) 'Thermogravimetric analysis of SPEEK membranes: thermal stability, degree of sulfonation and cross-linking reaction', J. Anal. Appl. Pyrol., Vol. 92, pp.361-365.

12 Chang, J.H., Park, J.H., Park, G.G., Kim, C.S. and Park, O.O. (2003) 'Proton-conducting composite membranes derived from sulfonated hydrocarbon and inorganic materials', J. Power Sources, Vol. 124, pp.18-25. 
13 Ye, H., Huang, J., Xu, J.J., Kodiweera, N.K.A.C., Jayakody, J.R.P. and Greenbaum, S.G. (2008) 'New membranes based on ionic liquids for PEM fuel cells at elevated temperatures', J. Power Sources, Vol. 178, No. 2, pp.651-660.

14 Baek, J.S., Park, J.S., Sekhon, S.S., Yang, T.H., Shul, Y.G. and Choi, J.H. (2010) 'Preparation and characterisation of non-aqueous proton-conducting membranes with the low content of ionic liquids', Fuel Cells, Vol. 10, No. 5, pp.762-769.

15 Han, M., Zhang, G., Li, M., Wang, S., Zhang, Y., Li, H. and Na, H. (2011) 'Considerations of the morphology in the design of proton exchange membranes: cross-linked sulfonated poly(ether ether ketone)s using a new carboxyl-terminated benzimidazole as the cross-linker for PEMFCs', Int. J. Hydrogen Energy, Vol. 36, No. 3, pp.2197-2206.

16 Kreuer, K.D. (2001) 'On the development of proton conducting polymer membranes for hydrogen and methanol fuel cells', J. Membr. Sci., Vol. 185, No. 1, pp.29-39.

17 Rangasamy, V.S., Thayumanasundaram, S., De Greef, N., Seo, J.W. and Locquet, J.P. (2012) 'Preparation and characterization of composite membranes based on sulfonated PEEK and $\mathrm{AlPO}_{4}$ for PEMFCs', Solid State Ionics, Vol. 216, pp.83-89.

18 Huang, R.Y.M., Shao, P., Burns, C.M. and Feng, X. (2001) 'Sulfonation of poly (ether ether ketone)(PEEK): kinetic study and characterization, J. Appl. Polym. Sci., Vol. 82, pp.2651-2660.

19 Xing, P., Robertson, G.P., Guiver, M.D., Mikhailenko, S.D., Wang, K. and Kaliaguine, S. (2004) 'Synthesis and characterization of sulfonated poly(ether ether ketone) for proton exchange membranes', J. Membr. Sci., Vol. 229, pp.95-106.

20 Cano-Serrano, E., Campos-Martin, J.M. and Fierro, J.L.G. (2003) 'Sulfonic acidfunctionalized silica through quantitative oxidation of thiol groups', Chem. Commun., No. 2, pp.246-247.

21 Gnana Kumar, G., Kim, A. R., Suk Nahm, K. and Elizabeth, R. (2009) 'Nafion membranes modified with silica sulfuric acid for the elevated temperature and lower humidity operation of PEMFC', Int. J. Hydrogen Energy, Vol. 34, No. 24, pp.9788-9794.

22 Othman, M.H.D., Ismail, A.F. and Mustafa, A. (2007) 'Proton conducting composite membrane from sulfonated poly (ether ether ketone) and boron orthophosphate for direct methanol fuel cell application', J. Membrane Sci., Vol. 299, pp.156-165.

23 Carbone, A., Pedicini, R., Portale, G., Longo, A., D’Ilario, L. and Passalacqua, E. (2006) 'Sulphonated poly(ether ether ketone) membranes for fuel cell application: thermal and structural characterisation', J. Power Sources, Vol. 163, No. 1, pp.18-26.

24 Di Noto, V., Piga, M., Giffin, G.A. and Pace, G. (2012) 'Broadband electric spectroscopy of proton conducting SPEEK membranes', J. Membr. Sci., Vol. 390-391, pp.58-67.

25 Reyna-Valencia, A., Kaliaguine, S. and Bousmina, M. (2006) 'Structural and mechanical characterization of poly(ether ether ketone) (PEEK) and sulfonated PEEK films: Effects of thermal history, sulfonation, and preparation conditions', J. Appl. Polym. Sci., Vol. 99, pp.756-774.

26 Zaidi, S.J., Mikhailenko, S.D., Robertson, G.P., Guiver, M.D. and Kaliaguine, S. (2000) 'Proton conducting composite membranes from polyether ether ketone and heteropolyacids for fuel cell applications', J. Membr. Sci., Vol. 173, No. 1, pp.17-34.

27 Mecheri, B., D'Epifanio, A., Pisani, L., Chen, F., Traversa, E., Weise, F.C. and Licoccia, S. (2009) 'Effect of a proton conducting filler on the physico-chemical properties of SPEEKbased membranes', Fuel Cells, Vol. 9 pp.372-380.

28 Knauth, P. and Schoonman, J. (Eds.) (2008) Nanocomposites: Ionic Conducting Materials and Structural Spectroscopies, Springer Science+Business Media, New York.

29 Menard, K.P. (1999) Dynamic Mechanical Analysis: A Practical Introduction, CRC Press LLC, Florida.

30 Sgreccia, E., Chailan, J.F., Khadhraoui, M., Di Vona, M.L. and Knauth, P. (2010) 'Mechanical properties of proton-conducting sulfonated aromatic polymer membranes: stress-strain tests and dynamical analysis', J. Power Sources, Vol. 195, No. 23, pp.7770-7775. 
31 Ye, G., Janzen, N. and Goward, G.R. (2009) 'Influence of water and degree of sulfonation on the structure and dynamics of SPEEK studied by solid-state ${ }^{13} \mathrm{C}$ and ${ }^{1} \mathrm{H}$ NMR', Polymer, Vol. 50, No. 12, pp.2664-2673.

32 Robertson, G.P., Mikhailenko, S.D., Wang, K., Xing, P., Guiver, M.D. and Kaliaguine, S. (2003) 'Casting solvent interactions with sulfonated poly(ether ether ketone) during proton exchange membrane fabrication', J. Membr. Sci., Vol. 219, pp.113-121.

33 Deivanayagam and Ramamoorthy (2012) 'Sulfonated Poly(ether ether ketone) and poly(ethylene glycol) diacrylate based semi-interpenetrating network membranes for fuel cells', J. Macromol. Sci. Part A Pure Appl. Chem., Vol. 49, pp.191-200.

34 Bauer, B., Jones, D. J., Roziere, J., Tchicaya, L., Alberti, G., Casciola, M. and Ramunni, E. (2000) 'Electrochemical characterisation of sulfonated polyetherketone membranes', J. New Mat. Electrochem. Syst., Vol. 3, pp.93-98.

35 Telfah, A., Majer, G., Kreuer, K. D., Schuster, M. and Maier, J. (2010) 'Formation and mobility of protonic charge carriers in methyl sulfonic acid-water mixtures: a model for sulfonic acid based ionomers at low degree of hydration', Solid State Ionics, Vol. 181, Nos. 11-12, pp.461-465.

36 Peron, J., Ruiz, E., Jones, D.J. and Rozière, J. (2008) 'Solution sulfonation of a novel polybenzimidazole: a proton electrolyte for fuel cell application', J. Membr. Sci., Vol. 314, Nos. 1-2 pp.247-256.

37 Parrondo, J., Ortueta, M. and Mijangos, F. (2007) 'Swelling behavior of PEMFC during conditioning', Braz. J. Chem. Eng [Online], http://www.scielo.br/scielo.php?pid=S010466322007000300010\&script $=$ sci_arttext\&tlng=es

38 Bishop, M.T., Karasz, F.E., Russo, P.S. and Langley, K.H. (1985) 'Solubility and properties of a poly(aryl ether ketone) in strong acids', Macromolecules, Vol. 18, No. 1, pp.86-93.

39 Díaz, I., Márquez-Alvarez, C., Mohino, F., Pérez-Pariente, J. and Sastre, E. (2000) 'Combined alkyl and sulfonic acid functionalization of MCM-41-type silica. Part I. Synthesis and characterization', J. Catal., Vol. 193, pp.283-294. 